\title{
Ultrasonography-Guided Radiofrequency Ablation for Painful Stump Neuromas to Relieve Postamputation Pain: A Pilot Study
}

This article was published in the following Dove Press journal:

Journal of Pain Research

\author{
Shaofeng Pu (D) \\ Junzhen $\mathrm{Wu}^{\prime}$ \\ Qingjian $\mathrm{Han}^{2}$ \\ Xin Zhang ${ }^{3}$ \\ Yingying Lv' \\ Yongming $\mathrm{Xu}^{\prime}$ \\ Chen $\mathrm{Li}^{1}$ \\ Dongping $\mathrm{Du}^{\prime}$
}

'Department of Pain Management, Shanghai Jiao Tong University Affiliated Sixth People's Hospital, Shanghai, 200233, People's Republic of China; ${ }^{2}$ Institutes of Brain Science, Fudan University, Shanghai 200032, People's Republic of China; ${ }^{3}$ Center for Translational Pain Medicine, Department of Anesthesiology, Duke University School of Medicine, Durham, NC 277I0, USA
Correspondence: Dongping Du Department of Pain Management, Shanghai Jiao Tong University Affiliated Sixth People's Hospital, Shanghai 200233, People's Republic of China

Tel +8621 24058896

Fax +86 21 24058330

Email dudp@sjtu.edu.cn
Objective: Postamputation pain (PAP) is a serious problem, and thus far, there is no perfect treatment strategy. Clinically, minimally invasive treatments for peripheral neuromas are simple and feasible. This study aimed to investigate the immediate and long-term effects of ultrasonography-guided radiofrequency ablation (RFA) on PAP.

Methods: Eighteen PAP subjects with painful peripheral neuromas were treated with ultrasonography-guided RFA.

Results: A total of 18 PAP subjects were included in the final analyses. Fourteen of the 17 subjects with residual limb pain (RLP) $(82.4 \%)$ had successful outcomes. A successful outcome was noted in 9 of the 13 subjects with phantom limb pain (PLP) (69.2\%). There were no significant associations between symptom relief and sex, age, or the duration of symptoms. There were no severe complications.

Conclusions: Ultrasonography-guided RFA for painful stump neuromas can effectively relieve stump pain and PLP in amputees with PAP (follow-up time was 12 months). Ultrasonography-guided RFA is easy and safe and does not involve radiation exposure, making it very suitable for clinical applications.

Keywords: postamputation pain, neuroma, ultrasonography-guided, radiofrequency ablation

\section{Introduction}

In 2005, an estimated 160,000 persons in the United States were living with limb loss, and by 2050 , the number of persons living with limb loss is expected to be higher than 3.6 million. ${ }^{1}$ Amputation itself is a very severe physical and psychological traumatic event, and up to $70-80 \%$ of patients with amputation also experience chronic complex postamputation pain, which can be devastating. ${ }^{2}$ Amputation can lead to three distinct types of pain or sensations, including residual limb pain (RLP), phantom limb pain (PLP), and phantom sensations. RLP refers to local pain at the amputation site in amputees. PLP refers to abnormal painful sensations in the missing limb. Phantom sensations refer to sensations resembling the presence of the missing limb after amputation. ${ }^{3}$ RLP usually coincides with PLP. ${ }^{4}$ More than half of the people with PLP also have RLP. ${ }^{5}$ Among amputees with moderate to severe PLP or RLP, pain, rather than the loss of a limb, is the most important factor affecting their ability to perform activities of daily living and hinders their ability to complete simple tasks, and this factor is strongly and negatively correlated with the time to return to employment or normal social participation. $^{5-7}$ 
The mechanism of PAP remains unclear. The interaction among peripheral, spinal and supraspinal mechanisms is believed to be responsible for PAP. ${ }^{8,9}$ Stump neuromas are important peripheral conditions that cause PAP. The formation of stump neuromas can lead to changes in receptor proteins, the expression of ion channels and the ectopic discharge of nerve terminals. ${ }^{10-12}$ Painful neuromas usually induce pain and prevent amputees from continuing to use prosthetic devices, which further limits their functional ability. ${ }^{13}$ It has been reported that the long-term outcomes of pulsed radiofrequency treatment for a huge neuroma stalk under ultrasonographic guidance are excellent. ${ }^{14}$ However, the information available about effective methods of radiofrequency therapy for PAP is very limited, and the procedural technology involved in this treatment is far from standardized. Here, we present a case series of 18 PAP subjects for whom we performed RFA. We aimed to obtain preliminary data on the efficacy of ultrasonography-guided RFA in treating RLP and PLP, as reported by PAP subjects, and the associated complications.

\section{Methods}

This study was approved by the ethics committee of Shanghai Sixth People's Hospital (No. 2017-125) and registered in the Chinese Clinical Trial Registry. The identifier is ChiCTR1800016566. The trial was registered on 9 June 2018, http://www.chictr.org.cn/edit.aspx?pid= $28183 \mathrm{andhtm}=4$. All procedures involving humans were performed in accordance with the ethical standards of the National Research Council. According to the Helsinki declaration, the researchers explained the significance of the study to all subjects and obtained written informed consent from the subjects. All medical records were anonymized, and no subject information was extracted for any reasons except for the purpose of the study.

\section{Participants and Clinical Evaluation}

Subjects from Shanghai Sixth People's Hospital in China were recruited from 11 June 2018 to 10 June 2019. The inclusion criteria of this study were as follows: 1 , adults aged 18 or older complaining of postamputation pain; 2 , those who underwent an amputation of the limb or part of the limb 3 months prior; and 3, those with painful neuromas in the stump of the amputation. The exclusion criteria were the presence of infection, coagulopathy, a pacemaker and a behavioral disorder that could impair subject cooperation. Subjects who were not willing to provide informed consent, underwent revision surgery less than three months ago, or had other diagnoses that could explain neuropathic pain were also excluded.

We recruited a total of 29 patients with postamputation pain. An experienced ultrasound specialist checked for the presence of nerve endings (neuromas). If a subject had a stump neuroma and agreed to join the study, we included the subject in the study. No obvious stump neuromas were found in the two patients, and three patients refused to participate in this study. Therefore, a total of 24 patients were enrolled in the study.

All enrolled subjects were examined by the same physician. The temperature of the inspection room was $22-24^{\circ} \mathrm{C}$, and the room was quiet. The subject's position was supine, prone or even lateral to facilitate the examination. The examining physician tapped the amputation stump to check for induced pain (including RLP and PLP). The Tinel sign was considered positive if tapping elicited tingling or the sensation of "pins and needles". If RLP or PLP was present, the intensity of pain was rated with a numerical rating scale (NRS). NRSs allow subjects to describe the intensity of his/ her pain as a number, usually ranging from 0 to 10 , where 0 means no pain and 10 means pain that is "as bad it could be". The frequency of PLP was also recorded. The examiner used ultrasound equipment (S-Nerve; SonoSite, Bothell, WA, USA) to detect whether there was neuroma in the stump. If there was a neuroma, the physician used $0.15 \%$ ropivacaine to perform a peripheral nerve block around the neuroma and observe it for 2 hours. If the subject's pain disappeared or was obviously reduced, the next step of radiofrequency treatment was carried out.

The Tinel sign was negative in five subjects, and these 5 subjects had no pain relief after a peripheral nerve block was performed around the neuroma, so we considered these subjects to not have painful neuromas. Thus, these subjects were excluded from this prospective study. It should be noted that one subject underwent residual neuroma resection one month after the three RFA treatments had been completed. He was considered lost to the 12-month RFA follow-up. Therefore, 18 cases were finally included in the statistical analysis (Figure 1).

\section{RFA Procedures}

The RFA procedures were performed as described by Xin Zhang et $\mathrm{al}^{15}$ with slight modifications. Specifically, the ultrasound probe was placed horizontally on the amputated stump of the subject to obtain the transverse axial view. The neuroma showed a hypoechoic shadow on ultrasonography 


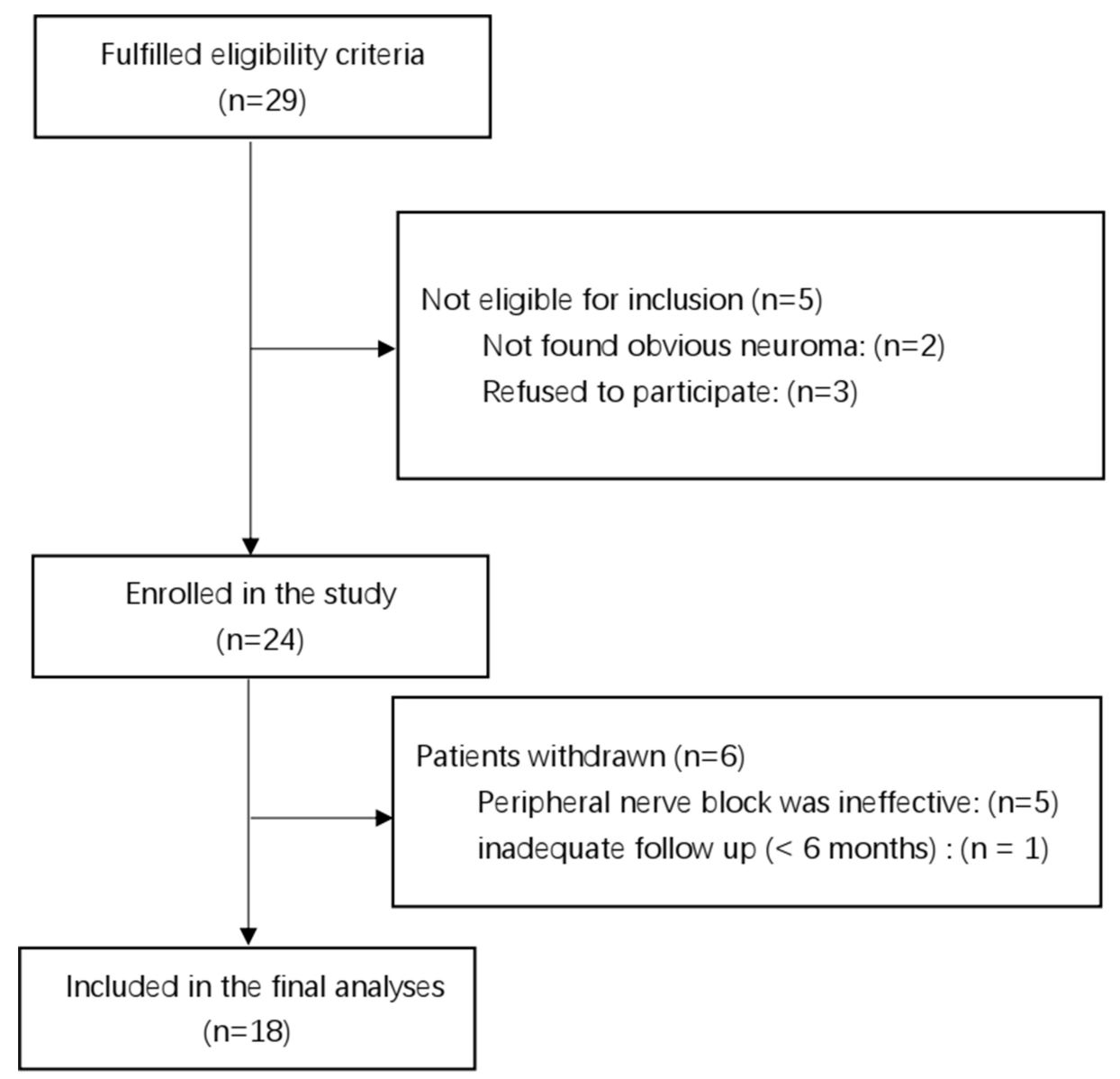

Figure I Flowchart for selecting study population.

(Figure 2). The color Doppler mode was used to differentiate between arteries/veins and nerves. When a stump neuroma was detected, we rotated the probe 75-90 degrees to explore

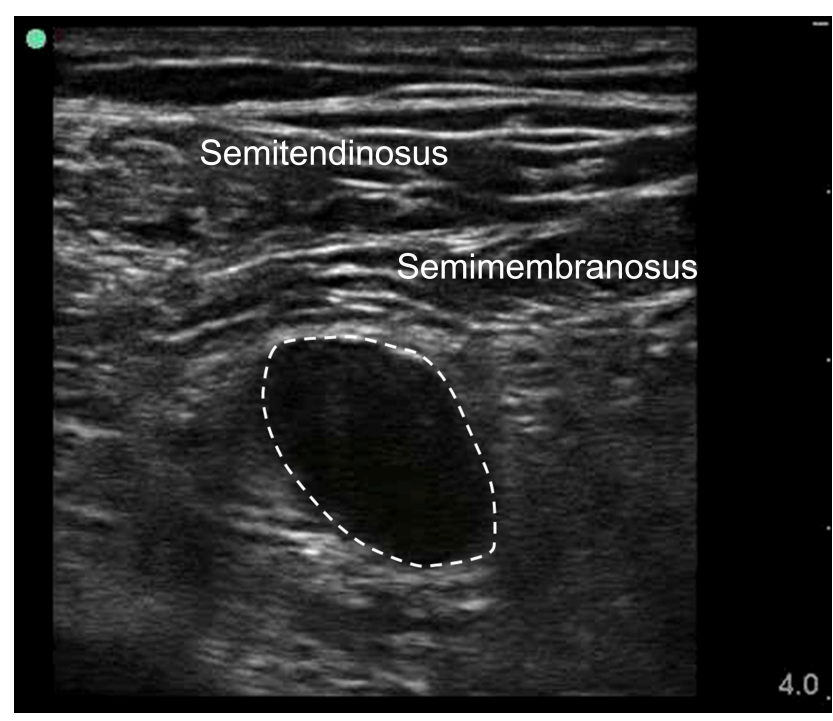

Figure 2 The ultrasonography of the stump neuroma. Dash line showed the neuroma hypoechoic shadow on ultrasonography. its long axis and moved the probe to the proximal extremity to explore the junction of the neuroma and the normal nerve (Figure 3). We assessed the size of the neuroma by examining the cross-sectional area in the long axis plane. A $10 \mathrm{~cm}$ radiofrequency needle with a $5 \mathrm{~mm}$ active tip was extended to the nerve, placed just outside the nerve, and connected to a radio frequency generator (Baylis company, Montreal, Canada). The nerve was then stimulated with the needle and the $0.4 \mathrm{~mA}$ sensory mode $(50 \mathrm{~Hz})$ to evoke pain in the subjects. When the target was confirmed, $2 \mathrm{~mL} 0.15 \%$ ropivacaine was injected through the needle. When the local anesthetic took effect, the needle was advanced into the responding neuroma to perform RFA at $80^{\circ} \mathrm{C}$ for 120 seconds (Figure 4). After the first RFA lesioning, the needle was moved from the initial target to the $0^{\circ}$ position of the neuroma, and RFA was performed again at $80^{\circ} \mathrm{C}$ for 120 seconds. Then, the needle was rotated clockwise for 30, 60, and 90 degrees until the entire 360-degree area of the neuroma was covered, and the same RFA procedures were performed. The needle was then directed to the middle of the neuroma, and RFA was performed at $80^{\circ} \mathrm{C}$ for 120 


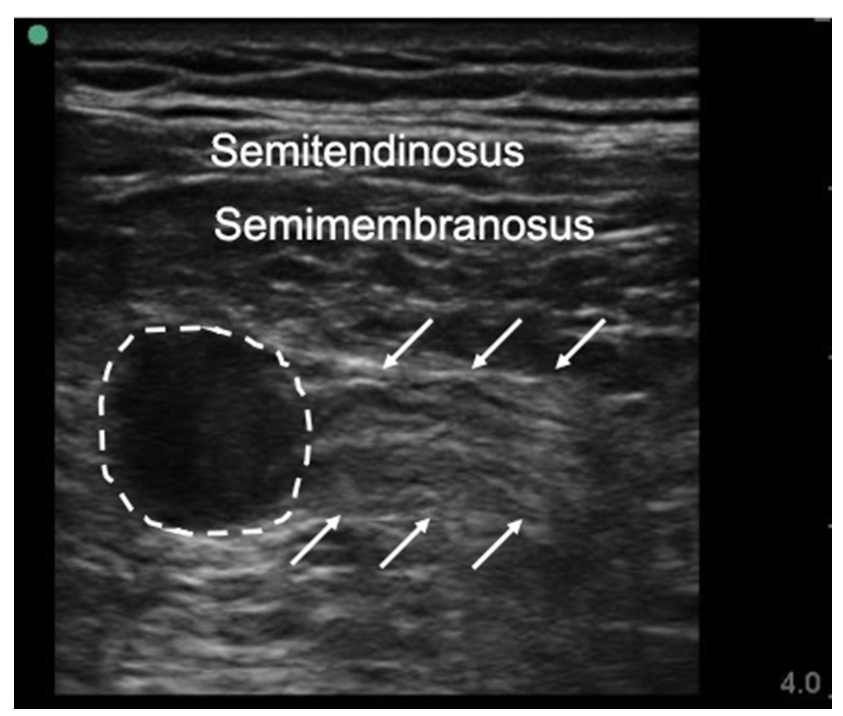

Figure 3 The ultrasonography of the long axis of the stump neuroma. The dash line indicated neuroma, and the arrow indicated nerve.

seconds. Before the needle was removed, a $5 \mathrm{~mL}$ mixture of $1.5 \%$ ropivacaine and compound betamethasone (including $5 \mathrm{mg}$ betamethasone propionic acid and $2 \mathrm{mg}$ betamethasone sodium phosphate) was injected around the neuroma. When there were multiple painful neuromas, we continued to follow the above procedure until all painful neuromas were treated.

\section{Clinical Assessment and Follow-Up}

All subjects were treated once every 2 weeks until the pain score was $\leq 3$. Each subject was treated up to three times. The treatment results were evaluated by a 5-point patient satisfaction scale, ie, 0 points for poor satisfaction, 1 point for general satisfaction, 2 points for good satisfaction, 3 points for very good satisfaction and 4 points for excellent satisfaction, and by using an NRS that ranged from 0 to 10 . The 5-point scale was based on that described in an article by Lee et al, ${ }^{16}$ and we revised it according to the scale described in an article by Zhang et al. ${ }^{15}$ Specifically, a score of 0 (poor) was recorded if the patient described experiencing any aggravation of pain. A score of 1 (fair) was recorded when the pain was $25 \%$ less severe than that before RFA. A score of 2 (good) indicated that the patient's pain had decreased by $\geq 25 \%$ but less than $50 \%$ with respect to that before RFA. If the pain was $\geq 50 \%$ but less than $75 \%$ less severe than that before RFA, a score of 3 points (very good) was recorded. A score of 4 (excellent) was assigned when the pain had completely resolved or the severity decreased by $\geq 75 \%$. A successful outcome required a patient satisfaction score of 3 (very good) or 4 (excellent) 12 months after RFA. The patients with a successful outcome were considered to have received effective treatment, and the other patients were considered to have received ineffective treatment. ${ }^{16}$

We recorded the preoperative NRS scores (RLP and PLP) of each subject and the number of treatments. Three posttreatment surveys were also administered to assess the subjects' NRS scores (RLP and PLP) after the last course of treatment. The first and second surveys were administered 2 weeks and 6 months after final treatment, while the last survey was administered 12 months after final treatment. We also recorded the frequency of PLP preoperatively (during the last week) and at 2 weeks, 6 months and 12 months after the final treatment (per week). The overall complications and recurrence results were also recorded.

\section{Statistical Analysis}

SPSS software, version 21.0 (IBM Corporation, Armonk, NY), was used to analyze all the statistical data. The measurement data are presented as the means \pm standard deviations. If the data conformed to a normal distribution, the $t$-test was used for analysis. The paired $t$-test was adopted to determine any significant differences between
A

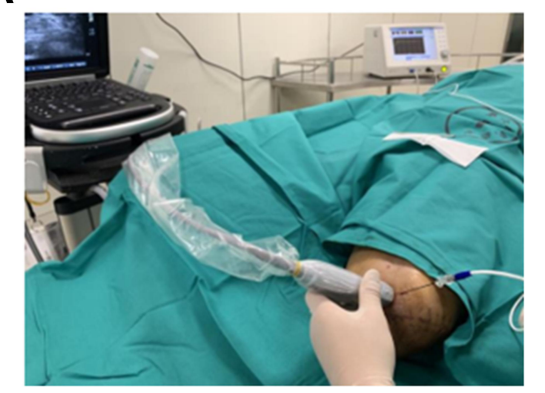

B

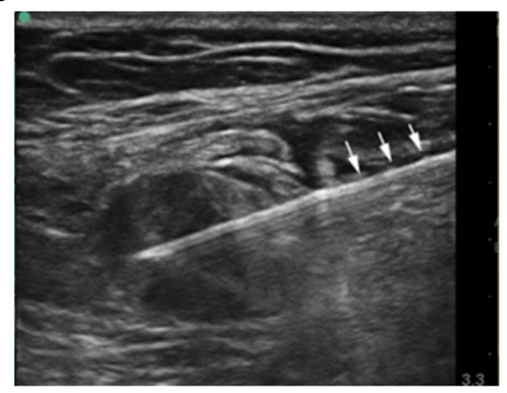

C

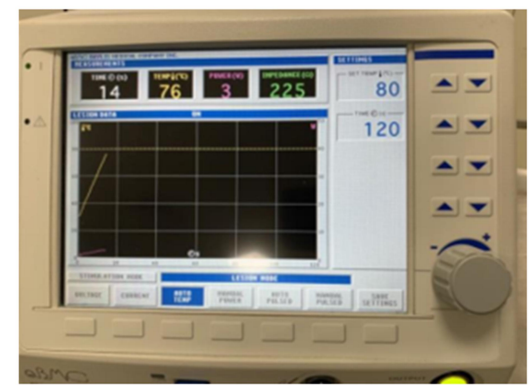

Figure 4 Radiofrequency ablation (RFA) treatment of PAP. (A) Ultrasound-guided RFA procedure. (B) RFA needle was advanced into the neuroma, arrow showed the needle. (C) Radiofrequency generator. 
the pre- and postoperative conditions. If the data did not conform to a normal distribution, the Wilcoxon test was used for analysis. $P$ values $<0.05$ were considered statistically significant.

\section{Results}

\section{Subject Characteristics}

A total of 18 adult subjects (11 men, 7 women; median age, 61.3 \pm 9.9 years; range, 47-81 years) who had undergone limb amputation (upper extremity, $\mathrm{n}=5$; lower extremity, $n=13$ ) were enrolled in this study. Among the subjects, there were 7 whose pain course was less than 1 year, 6 whose pain course was 1-5 years, and 5 whose pain course was more than 5 years. There were 15 cases of traumatic amputation, 2 cases of diabetic amputation and 1 case of arterial embolism of the lower extremity. A total of 23 painful neuromas were found in 18 patients, one was found in 13 patients, and two were found in 5 patients. The painful neuromas originated from the sciatic nerve $(8$ cases), tibial nerve (5 cases), peroneal nerve (3 cases), median nerve ( 3 cases), ulnar nerve ( 1 case), radial nerve ( 1 case), brachial plexus ( 1 case) and digital nerve ( 1 case, thumb). Seventeen subjects had RLP (94.4\%), 13 had PLP (72.2\%), and 12 had both PLP and RLP (66.7\%). The NRS score for preoperative pain was $8.6 \pm 1.0$ for RLP and 9.3 \pm 0.9 for PLP. The frequency of PLP before the treatment was 8.1 \pm 3.7 times per week (Table 1).

\section{Clinical Assessment}

We recorded the number of RFA treatments performed per subject. Six subjects received a total of three RFA treatments, 5 received two RFA treatments, and the remaining 7 received one treatment.

The NRS scores for RLP and PLP were recorded during preparation. Three posttreatment surveys for the NRS scores were completed by the subjects to quantify the degree of residual pain and phantom pain relief at 2 weeks, 6 months and 12 months after the final treatments. We also recorded the frequency of PLP per week. For RLP, the NRS score decreased from $8.6 \pm 1.0$ at preparation to $1.2 \pm 1.2(\mathrm{P}<0.001$, vs preoperatively) two weeks after treatment, while the NRS scores at 6 months and 12 months were $1.9 \pm 1.9(\mathrm{P}<0.001$, vs preoperatively $)$ and $2.2 \pm 2.1 \quad(\mathrm{P}<0.001$, vs preoperatively), respectively. For PLP, the NRS score decreased from $9.3 \pm 0.9$ before the operation to $2.2 \pm 1.8$ ( $\mathrm{P}<0.001$, vs preoperatively) at 2 weeks after treatment, while the NRS scores at 6 months
Table I Demographic Characteristics

\begin{tabular}{|c|c|}
\hline Numbers & 18 \\
\hline \multicolumn{2}{|l|}{$\operatorname{Sex}(n)$} \\
\hline Male & 11 \\
\hline Female & 7 \\
\hline \multicolumn{2}{|l|}{ Age (years) } \\
\hline Range & $47-81$ \\
\hline Mean \pm SD & $61.3 \pm 9.9$ \\
\hline \multicolumn{2}{|l|}{ Cause of amputation (n) } \\
\hline Trauma & $15(83.3 \%)$ \\
\hline Diabetes & 2 (II.I\%) \\
\hline Arterial embolism & $\mathrm{I}(5.6 \%)$ \\
\hline \multicolumn{2}{|l|}{ Amputation site } \\
\hline Lower limb, n (\%) & $13(72.2 \%)$ \\
\hline Below knee & 5 \\
\hline Above knee & 8 \\
\hline Upper limb, n (\%) & $5(27.8 \%)$ \\
\hline Should & I \\
\hline Above elbow & I \\
\hline Below elbow & 3 \\
\hline \multicolumn{2}{|l|}{ Painful neuroma distribution } \\
\hline Total & 23 \\
\hline Sciatic nerve & $8(34.8 \%)$ \\
\hline Tibial nerve & $5(21.7 \%)$ \\
\hline Peroneal nerve & $3(13.0 \%)$ \\
\hline Median nerve & $3(13.0 \%)$ \\
\hline Radial nerve & I (4.3\%) \\
\hline Ulnar nerve & I (4.3\%) \\
\hline Brachial plexus & I (4.3\%) \\
\hline Digital nerve (Thumb) & I (4.3\%) \\
\hline \multicolumn{2}{|l|}{ Duration of symptoms (years) } \\
\hline$<$ l year & 7 (38.9\%) \\
\hline I-5 years & $6(33.3 \%)$ \\
\hline$>5$ years & $5(27.8 \%)$ \\
\hline \multicolumn{2}{|l|}{ Type of pain, $n$ (\%): } \\
\hline Residual limb pain & 17 (94.4\%) \\
\hline Phantom limb pain & $13(72.2 \%)$ \\
\hline Both residual limb pain and phantom pain & $12(66.7 \%)$ \\
\hline \multicolumn{2}{|l|}{ Pain intensity, NRS $0-10, \mathrm{n}$} \\
\hline Residual limb pain & $8.6 \pm 1.0, n=17$ \\
\hline Phantom limb pain & $9.3 \pm 0.9, n=13$ \\
\hline \multicolumn{2}{|l|}{ Pain frequency } \\
\hline $\begin{array}{l}\text { The frequency of phantom limb pain during the } \\
\text { last week }\end{array}$ & $8.1 \pm 3.7$ \\
\hline
\end{tabular}

Abbreviation: NRS, numeric rating scale.

and 12 months were $2.9 \pm 2.5$ ( $\mathrm{P}<0.001$, vs preoperatively) and $3.2 \pm 2.7(\mathrm{P}<0.001$, vs preoperatively), respectively. The frequency of PLP per week decreased from 8.1 \pm 3.7 
A

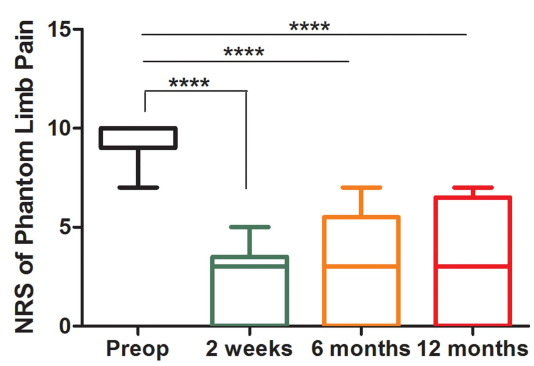

B

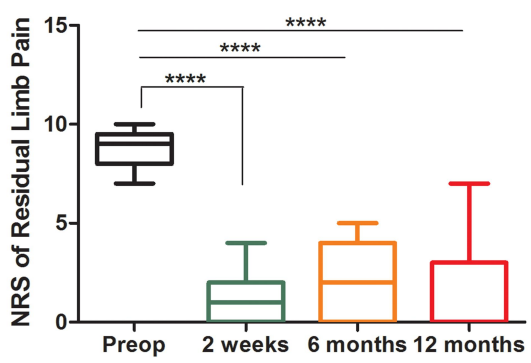

C

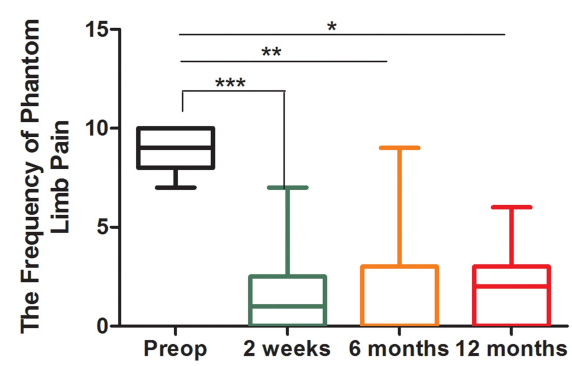

Figure 5 The assessment of the RFA of painful neuroma. NRS: Numeric rating scale; $* * * * \mathrm{P}<0.001, * * * \mathrm{P}=0.002, * * \mathrm{P}=0.005, * \mathrm{P}=0.003, \mathrm{vs}$ preoperatively.

times before the operation to $1.5 \pm 1.8(\mathrm{P}=0.002$, vs preoperatively) times at 2 weeks after treatment and $2.5 \pm 2.6$ $(\mathrm{P}=0.005$, vs preoperatively) times at the 6-month followup, while the frequency of PLP was $3.2 \pm 3.3$ ( $\mathrm{P}=0.003$, vs preoperatively) times at the 12-month follow-up (Figure 5).

With respect to subjective RLP relief, 1 subject exhibited fair outcomes, 2 exhibited good outcomes, 6 subjects exhibited very good outcomes, and 8 exhibited excellent outcomes. Thus, a successful outcome was noted in 14 of the 17 patients $(82.4 \%)$. With respect to subjective PLP relief, 1 subject exhibited fair outcomes, 3 exhibited good outcomes, 4 subjects exhibited very good outcomes, and 5 exhibited no residual symptoms (excellent). Thus, a successful outcome was noted in 9 of the 13 patients (69.2\%). There were no significant associations between symptom relief and sex, age, or the duration of symptoms ( $\mathrm{P}>0.05)$, as shown in Table 2 .

In one case of thumb neuroma, the pain disappeared after two RFA surgeries. After the last operation, there was

Table 2 Associations Between Sex, Duration of Symptoms (Years), Residual Limb Pain, Phantom Limb Pain and Symptom Relief

\begin{tabular}{|l|l|l|l|l|}
\hline Parameter & $\begin{array}{l}\text { Effective } \\
\text { Treatment }\end{array}$ & $\begin{array}{l}\text { Ineffective } \\
\text { Treatment }\end{array}$ & $\chi^{2}$ & P-value \\
\hline $\begin{array}{l}\text { Sex } \\
\text { Male } \\
\text { Female }\end{array}$ & 9 & 2 & 0.267 & 0.6052 \\
\hline $\begin{array}{l}\text { Duration of } \\
\text { symptoms (years) } \\
<\text { I year } \\
\text { I-5 years } \\
>5 \text { years }\end{array}$ & 5 & 2 & & \\
\hline $\begin{array}{l}\text { Type of pain } \\
\text { Residual limb pain } \\
\text { Phantom limb pain }\end{array}$ & 14 & 0 & 3.742 & 0.1539 \\
\hline
\end{tabular}

slight burning in the local tissue of the stump. There were no infections or other complications at the 12-month follow-up.

\section{Discussion}

The concept of a neuroma was first proposed by Odier in 1811. Neuromas are the result of the absence of normal continuity in nerves reconstructed after transection. ${ }^{17}$ When the distal nerve scaffold or its neurotrophic factor is deficient, the proximal end of an injured peripheral nerve forms a swelling neuroma. After traumatic amputation, these neuromas are particularly problematic due to the extent of nerve damage, the number of injured nerves, and the superficial location of these nerves in the stump. ${ }^{13}$ Furthermore, the amputation level and presence of a neuroma seem to affect the eventual diameters of the nerves. ${ }^{18}$ In our study, the prevalence of swollen neuromas was high, which is consistent with that in a study by Nina Stockfleth Buch et al, ${ }^{19}$ who reported that $79.1 \%$ of amputees had one or more neuromas. Furthermore, the proportion of neuromas in amputees with pain was as high as $81.2 \%$. These results are in line with the findings of 2 other studies, in which swollen neuromas were identified by ultrasound in 59 of $147(40.1 \%)^{20}$ and in 91 of 133 $(68.4 \%)^{21}$ amputees. However, we found a higher incidence of neuromas in patients with postamputation pain. Neuromas were found in 27 of 29 (93.1\%) patients with postamputation pain in our study. However, not all neuromas were symptomatic. In our study, the Tinel sign was negative in 5 of 24 patients (20.8\%), and a peripheral nerve block around the neuroma did not relieve their postamputation pain.

When a neuroma forms in the residual limb, it may result in enlarged and disorganized endings of $\mathrm{C}$ fibers and demyelinated A fibers that lead to an increased rate of spontaneous activity and related PAP. ${ }^{14}$ Neuromas area part of the repair process after peripheral nerve injury. 
Usually, a neuroma is formed at the distal end of the injured nerve. However, in some subjects, several neuromas grew on nerve endings. These neuromas resemble a gourd and cluster at the end of the same nerve fiber. ${ }^{15}$ In this study, one subject with an above-knee amputation had two neuromas that originated from the sciatic nerve. The stimulation of these two neuromas could reproduce all the subject's symptoms. A cohort study showed that the presence of PLP at a follow-up is significantly associated with the formation of a painful neuroma, ${ }^{22}$ which is in line with our observations.

There are few random controlled trials that can be used to guide physicians in selecting the optimal treatment for PAP. As indicated by multiple studies, PAP can be relieved by a peripheral nerve block to some extent. ${ }^{23}$ Treatments for peripheral nerves may be effective, such as radiofrequency, peripheral nerve stimulation, and regenerative peripheral nerves. ${ }^{13,15,24,25}$ Young Ki Kim et al ${ }^{24}$ reported that radiofrequency ablation guided by ultrasound is an effective treatment for PAP with a giant neuroma. In this study, we used ultrasonography-guided radiofrequency ablation to block peripheral ectopic inputs from painful neuromas in amputated limbs to reduce PAP. Ultrasound has the advantages of being accessible, inexpensive, and portable, allowing it to be used for real-time evaluations and to guide interventions. Therefore, it has become the preferred imaging method among doctors treating musculoskeletal issues. $^{26,27}$

RFA uses a high-frequency alternating current to induce coagulation necrosis of the target tissue. When the probe temperature is between $60^{\circ} \mathrm{C}$ and $80^{\circ} \mathrm{C}$, the tissue is destroyed. Since the temperature of the tissue decreases rapidly with the distance from the electrode tip, RFA is well defined and therefore has an advantage over chemical neurolysis. During RFA, the degree of tissue damage is related to the temperature of the tissue, the size of the electrode and the duration of the procedure. ${ }^{28}$

In this study, RFA effectively reduced the severity of long-term pain and burst pain in amputees. It should be noted that transection of the peripheral nerve could lead to overexcitation and spontaneous action potential discharge from the injured nerve bundle, which might be a potential source of PAP, including RLP and PLP. ${ }^{5}$ This mechanism might help explain why PLP was also relieved in our study. Borghi et $\mathrm{al}^{29}$ and Xin Zhang et $\mathrm{al}^{15}$ also reported that the treatment of peripheral nerves or neuromas could control PLP, which is consistent with our findings.
Moreover, we found that the phantom limb sensation in one above-knee amputation subject changed after RFA. The subject complained that the foot had an explosive twist of 270 degrees and that he could not subjectively correct this abnormal posture, which made him very distressed. The frequency of phantom limb sensation was 1-2 times a day, with each sensation lasting approximately half an hour. However, two weeks after RFA, the frequency of phantom limb sensation was reduced (two times in two weeks), and the sensation lasted for approximately half an hour. Moreover, his foot rotation angle had improved (only 90 degrees). At the one-year follow-up, the phantom limb sensation lasted approximately 15 minutes and occurred 2-4 times a month, with a rotation angle of 60-90 degrees. Moreover, the phantom limb sensation could be corrected subjectively. This finding showed that the treatment of a painful neuroma can not only improve postamputation pain but also improve phantom limb sensations. This finding could serve as motivation for future research.

It should be noted that one subject with PLP had no obvious pain relief two weeks after three RFA treatments and then underwent residual neuroma resection one month later. The PLP disappeared completely after the resection of his neuroma, and the NRS score was 0 at the 6-month follow-up. Because neuroma resection was performed at the nerve end approximately $2 \mathrm{~cm}$ away from the neuroma (Supplementary Figure 1), it seems that painful neuroma was not the only cause of postamputation pain, and the local microenvironment of the peripheral nerve and stump may also play a role.

\section{Limitations}

This study was not a randomized controlled study, and only a few cases were included.

\section{Conclusions}

This pilot study showed that ultrasonography-guided RFA treatment of painful neuromas can effectively reduce postamputation pain. Moreover, RFA was shown to improve intolerable phantom limb sensations in one subject. Ultrasonography-guided RFA of residual painful neuromas is a simple, safe, radiation-free and effective procedure that provides sustained pain relief in postamputation pain subjects. This clinical study also suggests that radiofrequency ablation of the neuromas and nerve stump at the same time may be a feasible choice in the future. It is suggested that peripheral mechanisms play an important role in postamputation pain. 


\section{Data Sharing Statement}

We all agree to share all the data about this article. We will also share unpublished data, such as the size of the neuromas. The data will be available on: http://blog.sina.com. $\mathrm{cn} / \mathrm{u} / 2759448832$.

\section{Acknowledgments}

This work was supported through a grant from Shanghai Municipal Health Commission, No. 201840248 (Shaofeng $\mathrm{Pu}$ ), and the General Program of National Natural Science Foundation of China, No. 81672237 (Dongping Du). We thank Fang Tong for helping with the statistical analysis. We also gratefully thank Xing $\mathrm{Gu}$ for her comments on the manuscript.

\section{Disclosure}

The authors declare that they have no conflicts of interest.

\section{References}

1. Ziegler-Graham K, MacKenzie EJ, Ephraim PL, et al. Estimating the prevalence of limb loss in the United States: 2005 to 2050. Arch Phys Med Rehabil. 2008;89(3):422-429. doi:10.1016/j.apmr.2007.11.005

2. Ephraim PL, Wegener ST, MacKenzie EJ, et al. Phantom pain, residual limb pain, and back pain in amputees: results of a national survey. Arch Phys Med Rehabil. 2005;86(10):1910-1919. doi:10.1016/j.apmr.2005.03.031

3. Nikolajsen L, Jensen TS. Phantom limb pain. Br J Anaesth. 2001;87 (1):107-116. doi:10.1093/bja/87.1.107

4. Nikolajsen L, Ilkjaer S, Kroner K, et al. The influence of preamputation pain on postamputation stump and phantom pain. Pain. 1997;72 (3):393-405. doi:10.1016/S0304-3959(97)00061-4

5. Hanyu-Deutmeyer AA, Cascella M, Varacallo M. Phantom Limb Pain. In: StatPearls. edn ed. Treasure Island (FL); 2019. Available from: https://www.ncbi.nlm.nih.gov/books/NBK448188/. Accessed December 14, 2020.

6. Noguchi S, Saito J, Nakai K, et al. Factors affecting phantom limb pain in patients undergoing amputation: retrospective study. $J$ Anesth. 2019;33(2):216-220. doi:10.1007/s00540-018-2599-0

7. Rudy TE, Lieber SJ, Boston JR, et al. Psychosocial predictors of physical performance in disabled individuals with chronic pain. Clin J Pain. 2003;19(1):18-30. doi:10.1097/00002508-200301000-00003

8. Hsu E, Cohen SP. Postamputation pain: epidemiology, mechanisms, and treatment. J Pain Res. 2013;6:121-136.

9. Nikolajsen L. Postamputation pain: studies on mechanisms. Dan Med J. 2012;59(10):B4527.

10. Woo SL, Kung TA, Brown DL, et al. Regenerative peripheral nerve interfaces for the treatment of postamputation neuroma pain: a pilot study. Plast Reconstr Surg Glob Open. 2016;4(12):e1038. doi:10.10 97/GOX.0000000000001038

11. Cohen SP, Gambel JM, Raja SN, Galvagno S. The contribution of sympathetic mechanisms to postamputation phantom and residual limb pain: a pilot study. J Pain. 2011;12(8):859-867. doi:10.1016/j. jpain.2011.01.009
12. Aternali A, Katz J. Recent advances in understanding and managing phantom limb pain. F1000Research. 2019;8.

13. Souza JM, Cheesborough JE, Ko JH, et al. Targeted muscle reinnervation: a novel approach to postamputation neuroma pain. Clin Orthop Relat Res. 2014;472(10):2984-2990. doi:10.1007/s11999014-3528-7

14. West $\mathrm{M}, \mathrm{Wu} \mathrm{H}$. Pulsed radiofrequency ablation for residual and phantom limb pain: a case series. Pain Pract. 2010;10(5):485-491. doi:10.1111/j.1533-2500.2009.00353.x

15. Zhang $\mathrm{X}, \mathrm{Xu} \mathrm{Y,} \mathrm{Zhou} \mathrm{J,} \mathrm{et} \mathrm{al.} \mathrm{Ultrasound-guided} \mathrm{alcohol} \mathrm{neurolysis}$ and radiofrequency ablation of painful stump neuroma: effective treatments for post-amputation pain. J Pain Res. 2017;10:295-302. doi:10.2147/JPR.S127157

16. Lee JW, Kim SH, Choi JY, et al. Transforaminal epidural steroid injection for lumbosacral radiculopathy: preganglionic versus conventional approach. Korean J Radiol. 2006;7(2):139-144. doi:10.33 48/kjr.2006.7.2.139

17. Marcol W, Kotulska K, Larysz-Brysz M, et al. Prevention of painful neuromas by oblique transection of peripheral nerves. J Neurosurg. 2006;104(2):285-289. doi:10.3171/jns.2006.104.2.285

18. Goktepe AS, Ozcakar L, Komurcu E, et al. Sonographic evaluation of the sciatic nerve in patients with lower-limb amputations. Muscle Nerve. 2010;41(6):763-766. doi:10.1002/mus.21607

19. Buch NS, Qerama E, Brix Finnerup N, Nikolajsen L. Neuromas and postamputation pain. Pain. 2020;161(1):147-155. doi:10.1097/j.pain. 0000000000001705

20. Aydemir K, Demir Y, Guzelkucuk U, et al. Ultrasound findings of young and traumatic amputees with lower extremity residual limb pain in Turkey. Am J Phys Med Rehabil. 2017;96(8):572-577. doi:10. 1097/PHM.0000000000000687

21. O'Reilly MA, O'Reilly PM, O'Reilly HM, et al. High-resolution ultrasound findings in the symptomatic residual limbs of amputees. Mil Med. 2013;178(12):1291-1297. doi:10.7205/MILMED-D-1300273

22. Penna A, Konstantatos AH, Cranwell W, et al. Incidence and associations of painful neuroma in a contemporary cohort of lower-limb amputees. ANZ J Surg. 2018;88(5):491-496. doi:10.1111/ans.14293

23. Shankar H. Ultrasound-guided sciatic neuroma block for treatment of intractable stump pain. J Clin Anesth. 2008;20(6):483-484. doi:10.10 16/j.jclinane.2008.05.006

24. Kim YK, Jung I, Lee CH, et al. Pulsed radiofrequency ablation under ultrasound guidance for huge neuroma. Korean J Pain. 2014;27 (3):290-293. doi:10.3344/kjp.2014.27.3.290

25. Kubiak CA, Kemp SWP, Cederna PS. Regenerative peripheral nerve interface for management of postamputation neuroma. JAMA Surg. 2018;153(7):681-682. doi:10.1001/jamasurg.2018.0864

26. Chiu YH, Chang KV, Chen IJ, et al. Utility of sonoelastography for the evaluation of rotator cuff tendon and pertinent disorders: a systematic review and meta-analysis. Eur Radiol. 2020;30 (12):6663-6672. doi:10.1007/s00330-020-07059-2

27. Chang PH, Chen YJ, Chang KV, et al. Ultrasound measurements of superficial and deep masticatory muscles in various postures: reliability and influencers. Sci Rep. 2020;10(1):14357. doi:10.1038/s415 98-020-71378-z

28. Byrd D, Mackey S. Pulsed radiofrequency for chronic pain. Curr Pain Headache Rep. 2008;12(1):37-41. doi:10.1007/s11916-0080008-3

29. Borghi B, D'Addabbo M, Borghi R. Can neural blocks prevent phantom limb pain? Pain Manag. 2014;4(4):261-266. doi:10.2217/ pmt.14.17 


\section{Publish your work in this journal}

The Journal of Pain Research is an international, peer reviewed, open access, online journal that welcomes laboratory and clinical findings in the fields of pain research and the prevention and management of pain. Original research, reviews, symposium reports, hypothesis formation and commentaries are all considered for publication. The manuscript management system is completely online and includes a very quick and fair peer-review system, which is all easy to use. Visit http:// www.dovepress.com/testimonials.php to read real quotes from published authors. 